\title{
A randomized trial in comparison between planned cesarean and vaginal delivery on twin pregnancy
}

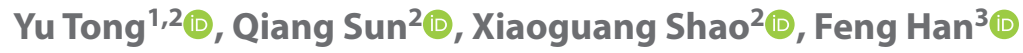 \\ ${ }^{1}$ Department of Obstetrics and Gynecology, Nanfang Hospital, Southern Medical University, Guangzhou, Guangdong, China \\ ${ }^{2}$ Department of Obstetrics and Gynecology, Dalian Municipal Women and Children's Medical Center, Dalian, Liaoning, China \\ ${ }^{3}$ Department of Hand and Microsurgery, The First Affiliated Hospital of Dalian Medical University, Dalian, Liaoning, China
}

\begin{abstract}
Objective: We explored the planned cesarean to vaginal delivery at the risk of fetal or neonatal death or serious neonatal morbidity in women with twin pregnancies.

Material and methods: Three hundred and forty-three pregnant women were divided into planned cesarean delivery (PCD) and vaginal delivery (PVD) groups (208 vs 135). In the planned-cesarean-delivery group, the rate of cesarean delivery was $98.82 \%$. Meanwhile, the rate of vaginal delivery was $51.27 \%$ in PVD group.

Results: Women in the PCD group delivered earlier than that in the PVD group. However, the composite primary outcome of the PCD group was like that of the PVD group. Certainly, the odds ratio of planned cesarean delivery and confidence interval of the PCD group was also like those of the PVD group.

Conclusions: The risk of fetal or neonatal death or serious neonatal morbidity of planned-vaginal-delivery was like those of planned-vaginal-delivery in pregnant women with twin pregnancies.
\end{abstract}

Key words: planned cesarean; vaginal delivery; twin pregnancy

Ginekologia Polska 2020; 91, 10: 600-606

\section{INTRODUCTION}

Twin gestations accounts for $3 \%$ of all deliveries and has different risk characteristics than singleton gestations [1, 2]. It has been reported that in recent years, the cesarean section rate of multiple pregnancies has gradually increased to more than $70 \%$ [3]. The main reason for the rise of caesarean section (CS) rate in the world is maternal-choice CS (MCCS) [4]. Twin pregnancies appear to be an independent risk factor for cesarean births after induction of labor, but more than three-quarters of inductions culminated in vaginal delivery [5]. Implementation of the National Institute for Health and Care Excellence (NICE) guidance on the antenatal management of uncomplicated twin pregnancies contributed to significant reduction (>70\%) in stillbirth has been noted in twin pregnancies in UK [6].

However, compared with singleton pregnancies, complications of gemellary pregnancies are obviously higher [7]. During gemellary pregnancies, it is more likely to have abortions, fetal malformations, polyhydramnios, preeclampsia and premature delivery, etc. [8]. During the stages of labor, complications such as dystocia, prolapse of cord and postpartum hemorrhage are more likely to occur [9]. As recent cesarean section rates in China are abnormally increasing, most gemellary pregnancies would be performed in the way of caesarean sections [10]. However, a gemellary pregnancy is not the absolute indication for cesarean delivery. Furthermore, when the heads of two fetuses or the first fetus head appears, vaginal delivery is principally feasible. Vaginal delivery is demanded by some gemellary pregnant women [11].

The selection of delivery time has no single standard by now. Generally, most gemellary pregnant women without complications would be admitted to hospital between the $36^{\text {th }} \sim 39^{\text {th }}$ weeks [12]. The lowest fetal mortality and neonatal mortality rate occur between the $38^{\text {th }}$ and $39^{\text {th }}$ weeks, respectively. Consequently, it is generally suggested that gemellary pregnancies should be terminated before the $39^{\text {th }}$ week. At present, caesarean sections are regarded as a relatively effective method for high risk pregnancy women and has been widely accepted and employed [13]. As society is constantly advancing and medical modes are continuously changing, rates of caesarean births are ascending steadily [14].

The Twin Birth Study, a recent randomized controlled trial of 2804 women with twin pregnancies, showed that the first twin presented in cephalic position to planned vaginal delivery or planned cesarean. All in all, there were 
no differences in neonatal and maternal outcome between the planned vaginal delivery and planned cesarean groups [15]. However, the design of the Twin Birth Study has always been controversial [16]. In this study, most women delivered shortly after the 32 weeks. Prematurity has a great influence on the neonatal outcomes, so it may include the influence of the way of full-term planned delivery. The subgroup of women that was randomized after 37 weeks was small and it was not clear which was the best method of delivery in twin pregnancy at term, although the less morbidity was observed after planned caesarean delivery. Whether the outcomes of the Twin Birth Study are completely applicable to other settings are still unknown [17].

Cesareans are not a physiological suitable means of pregnancy. As a traumatic surgery, it has many disadvantages and would bring about some problems for women. Besides, women after caesarean are more likely to have massive haemorrhaging, wound infection, scarred uterus or various complications [18]. As far as women who have subsequent pregnancies are concerned, they are confronted with the issue how to select their subsequent pregnancy methods [12]. This study was carried out to compare planned cesarean to vaginal delivery at the risk of fetal or neonatal death or serious neonatal morbidity in pregnant women with twin pregnancies.

\section{MATERIAL AND METHODS Study design}

Women permitted to participate in the study had pregnancies with twins ranging from 32 weeks to 39 weeks, with the head of the first twin appearing earlier than the second during birth and with the two fetuses staying alive with weight from $1500 \mathrm{~g}$ to $4000 \mathrm{~g}$, which was authenticated via ultrasonography within a week prior to randomization. Women were recruited with pregnancies as early as 32 weeks of gestation inasmuch as the number of women with twins intend to start a choice of the method of delivery at this time and a host of twins are born prematurely.

\section{Study oversight}

Women with the following conditions were excluded from the study: monoamniotic twins, the number of fetuses reduced at more than 13 weeks of gestation, anomalous fetus that is fatal, contraindication to labor or vaginal delivery, and prior participation in the Twin Birth Study.

\section{Treatment}

Our protocol, whose full text is available at NEJM.org, was approved by the research ethics committee at each participating center. All women participants, prior to the enrolment, provided the informed consent in written form. The first, second and last authors oversee the exactitude and integrity of all data and the correspondence of the report with integrity.

Those participating were distributed to planned cesarean delivery (PCD) and vaginal delivery (PVD) groups at random. Randomization was kept under control at the Centre for Mother, Infant, and Child Research at Sunnybrook Health Sciences Centre in Toronto with the assistance of a computerized program of randomization which was layered in line with parity ( 0 vs $\geq 1$ ) and gestational age ( 224 days to 237 days, 238 days to 258 days, or 259 days to 272 days).

\begin{tabular}{|c|c|c|}
\hline Characteristic & Cesarean deliver $(n=208)$ & Vaginal delivery $(n=135)$ \\
\hline Previous cesarean section & $7(3.37 \%)$ & $5(3.70 \%)$ \\
\hline Age $\geq 30$-year age & $87(41.83 \%)$ & $59(43.70 \%)$ \\
\hline Mean age & $31.6 \pm 0.9$ & $31.9 \pm 0.7$ \\
\hline 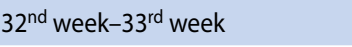 & $61(29.32 \%)$ & $41(30.37 \%)$ \\
\hline $34^{\text {th }}$ week- $36^{\text {th }}$ week & $101(48.56 \%)$ & $67(49.63 \%)$ \\
\hline $37^{\text {th }}$ week-38 $8^{\text {th }}$ week & $46(22.12 \%)$ & $27(20.00 \%)$ \\
\hline \multicolumn{3}{|l|}{ Fetal weight } \\
\hline First twin & $1179 \pm 411$ & $1184 \pm 409$ \\
\hline Second twin & $1166 \pm 406$ & $1176 \pm 405$ \\
\hline \multicolumn{3}{|l|}{ Chorionicity } \\
\hline Dichorionic and diamnionic & $142(68.27 \%)$ & $91(67.41 \%)$ \\
\hline Monochorionic and diamnionic & $57(27.40 \%)$ & $38(28.15 \%)$ \\
\hline Unknown & $9(4.32 \%)$ & $6(4.44 \%)$ \\
\hline Not in labor & $181(87.02 \%)$ & $119(88.15 \%)$ \\
\hline Membranes ruptured & $11(5.29 \%)$ & $7(5.19 \%)$ \\
\hline
\end{tabular}


Experienced staff members accumulated data from the medical records at each participating center and kept them on file, following labor, on standardized forms for data collection. Participating centers made an evaluation of the growth and well-being of fetuses by means of ultrasonography every four weeks at the minimum by stress free or biophysical profile test twice/week if need be. Preparations were made for possible cesarean sections within thirty minutes as the need arose; and at the time of planned vaginal delivery members in the hospital related to anesthesia, obstetrics and nursing were placed on standby.

Alternative delivery by way of either cesarean section (PCD group) or labor induction (PVD group) was organized between 264 to 272 days of gestation, so far as there was some evidence that at this gestational — age window perinatal conditions would yield the best possible results. Provided the first twin was brought into the world through vaginal means by a woman in the planned-cesarean group, the second twin would be delivered in the same manner, if logistically possible. In regards to women who were scheduled to have a vaginal delivery, it was expected that no less than $60 \%$ would give birth to both twins by vaginal means. At the time of delivery, there was a reassessment of the pregnancy; in case of a contraindication to labor or vaginal delivery, both twins would be born via caesarean section. Standard methods were utilized in case of induced labor, but for women with a previous caesarean section, advocacy of prostaglandins was not permitted.

Constant monitoring of the fetal heart rate by electronic means was approved in course of active labor. The obstetrician was authorized to make a decision regarding the application of oxytocin and epidural analgesia. Following the first twin birth, it would be advisable to make use of ultrasonography to examine the state of the second twin. In the event the twin would be born with the head appearing first, amniotomy was postponed until the head was engaged and natural vaginal delivery was planned, only when an unsatisfactory position necessitated the usage of forceps or vacuum extraction. Assuming the second twin did not remain in the cephalic presentation, the obstetrician was free to decide about the optimum method of delivery.

Those scheduled to have a vaginal delivery were accompanied by a competent obstetrician adept at vaginal twin delivery. This was interpreted a priori, an obstetrician who themselves had at vaginal twin delivery and whose department head saw eye to eye with this judgment. Prior to the recruitment at each center, a number code was assigned to each of the competent obstetricians who considered themselves qualified in vaginal twin birth, as well as their years of service with vaginal twin delivery and information was kept on file. In addition, collection of information about similar items for other clinicians present during delivery was also made.

Infants are born with positive-pressure ventilation, tracheal intubation, oxygen, intravenous therapy, blood transfusion, surfactant, or a combination of these therapies, if needed. An assessment of intracranial pathology was made by means of neonatal ultrasonography if so, specified in a clinical sense.

\section{Outcomes}

Regarding the current analysis, both mothers and their neonates were kept track of until 28 days after the delivery. The principal outcome was a combination of mortality of fetuses or neonates or life-threatening diseases for neonates. Assessment of neonatal mortality was made between day 1 and day 27 following the birth. Life-threatening diseases for neonates were interpreted as the following: birth trauma (spinal cord injury, basal or depressed skull fracture, fracture of a long bone, harm done to a peripheral nerve manifesting itself within $72 \mathrm{~h}$ after birth or at discharge, subdural or intracerebral hemorrhage substantiated through the agency of ultrasonography, CT, or MRI, APGAR score of no more than 4 to $5 \mathrm{~min}$, coma, stupor, or slowed-down response to pain, minimum of two seizures before $72 \mathrm{~h}$ since birth, requirement of assisted ventilation by way of an endotracheal tube interpolated within $72 \mathrm{~h}$ following birth and kept in place for $24 \mathrm{~h}$ at the minimum, septicemia authenticated by way of blood culture or meningitis authenticated by means of cerebrospinal fluid culture within $72 \mathrm{~h}$ after birth, necrotizing enterocolitis, interpreted as intestinal perforation, pneumatosis intestinalis, or air in the portal vein diagnosed via surgery or radiography, bronchopulmonary dysplasia, interpreted as the requirement for additional oxygen at a postnatal gestational age of 36 weeks and authenticated by way of radiography, intraventricular hemorrhage or cystic periventricular leukomalacia. Data about newborn babies with the principal outcomes were evaluated with such information as the assigned group and mode of delivery (if applicable) kept dark by an adjudication committee.

\section{Statistical analysis}

Another result was an amalgam of death of a mother or mother's grave illness within $\mathbf{2 8}$ days following childbirth, interpreted as the following: death, hemorrhage (blood loss $\geq 1500 \mathrm{~mL}$, need for blood transfusion, or need for dilation and curettage after delivery), laparotomy, genital tract injury (need for hysterectomy; vulvar or perineal hematoma requiring evacuation; broad-ligament hematoma authenticated by means of ultrasonography, $\mathrm{CT}$, or MRI; intraoperative damage to the bladder, ureter, or bowel requiring repair; fistula involving the genital 
Table 2. Characteristics of labor and delivery for pregnant woman

\begin{tabular}{|c|c|c|}
\hline Characteristic & Cesarean deliver $(n=208)$ & Vaginal delivery $(n=135)$ \\
\hline \multicolumn{3}{|l|}{ Mode of delivery } \\
\hline Cesarean & 187 (89.90\%) & $51(37.77 \%)$ \\
\hline Vaginal and cesarean & $2(0.96 \%)$ & $7(5.19 \%)$ \\
\hline Vaginal for both & $19(9.13 \%)$ & $77(57.04 \%)$ \\
\hline \multicolumn{3}{|l|}{ Timing of cesarean section } \\
\hline Before the onset of labor & $109(52.40 \%)$ & $19(14.07 \%)$ \\
\hline During labor & $65(31.25 \%)$ & $42(31.11 \%)$ \\
\hline No cesarean section & $34(16.35 \%)$ & 74 (54.81\%) \\
\hline \multicolumn{3}{|l|}{ Presentation at delivery } \\
\hline \multicolumn{3}{|l|}{ Cephalic presentation } \\
\hline Cephalic and noncephalic presentation & $142(68.27 \%)$ & $91(67.41 \%)$ \\
\hline Noncephalic and cephalic or noncephalic presentation & $57(27.40 \%)$ & $38(28.15 \%)$ \\
\hline Gestational age at delivery & $9(4.32 \%)$ & $6(4.44 \%)$ \\
\hline Not in labor & $181(87.02 \%)$ & $119(88.15 \%)$ \\
\hline Membranes ruptured & $11(5.29 \%)$ & $7(5.19 \%)$ \\
\hline \multicolumn{3}{|l|}{ Gestational age at delivery of first twin } \\
\hline \multicolumn{3}{|l|}{ Mean age } \\
\hline $32^{\text {nd }}$ week- $33^{\text {rd }}$ week & $11(5.29 \%)$ & $4(2.96 \%)$ \\
\hline $34^{\text {th }}$ week- $36^{\text {th }}$ week & $84(40.38 \%)$ & $58(42.96 \%)$ \\
\hline $37^{\text {th }}$ week-38 $38^{\text {th }}$ week & $109(52.40 \%)$ & $69(51.11 \%)$ \\
\hline$>39^{\text {th }}$ week & $4(1.92 \%)$ & $4(2.96 \%)$ \\
\hline Time from randomization to delivery of first twin & $12.2 \pm 12.1$ days & $13.4 \pm 12.2$ days \\
\hline Interval between deliveries & $3.3 \pm 9.6 \mathrm{~min}$ & $10.2 \pm 17.4 \mathrm{~min}$ \\
\hline Use of antenatal glucocorticoids after randomization & $25(12.02 \%)$ & $14(10.37 \%)$ \\
\hline \multicolumn{3}{|l|}{ Chorionicity at birth } \\
\hline Dichorionic and diamnionic & $149(71.63 \%)$ & $97(71.85 \%)$ \\
\hline Dichorionic and diamnionic & $42(20.19 \%)$ & $30(22.22 \%)$ \\
\hline Dichorionic and diamnionic & $1(0.48 \%)$ & $1(0.74 \%)$ \\
\hline Unknown & $16(7.69 \%)$ & $7(5.19 \%)$ \\
\hline Use of anesthesia or analgesia & $201(96.63 \%)$ & $95(70.37 \%)$ \\
\hline Regional & $192(95.52 \%)$ & $73(76.84 \%)$ \\
\hline General & $13(6.47 \%)$ & $6(6.32 \%)$ \\
\hline Other & 4 (1.99\%) & 10 (10.52\%) \\
\hline
\end{tabular}

tract; or third-degree or fourth-degree perineal laceration involving the anal sphincter or mucosa, thromboembolism requiring anticoagulant therapy, systemic infection, serious illness that is life-threatening, wound infection that calls for prolonged hospitalization, readmission to the hospital, or repeated treatment as an outpatient, wound dehiscence or breakdown; or other grievous maternal complication. Other detrimental factors except morbidity defined beforehand were supposed to be presented to the independent board for monitoring data and safety.
Subordinate results to be presented later encompassed death, an unsatisfactory neurodevelopmental outcome for children two years of age and troublesome urinary, fecal, or flatal incontinence for mothers two years following childbirth. There were additional results for mothers, inclusive of contentment with the mode of delivery, breast-feeding, quality of life, tiredness and melancholia.

The data are expressed as the mean \pm standard deviation and conducted using SPSS 17.0 (SPSS, Inc., Chicago, IL, USA). Statistical analysis was performed where appropriate, and the Student-Newman-Keuls method was used for pairwise 
Table 3. Pregnancies outcomes

\begin{tabular}{|c|c|c|}
\hline Characteristic & Cesarean deliver $(n=208)$ & Vaginal delivery $(n=135)$ \\
\hline No. of fetuses or infants included in analysis & 418 & 271 \\
\hline Primary outcome & $8(1.91 \%)$ & $6(2.21 \%)$ \\
\hline \multicolumn{3}{|l|}{ Gestational age } \\
\hline $32^{\text {nd }}$ week-33 $33^{\text {rd }}$ week & 6 & 4 \\
\hline $34^{\text {th }}$ week-36 $36^{\text {th }}$ week & 2 & 2 \\
\hline $37^{\text {th }}$ week-38 $8^{\text {th }}$ week & 0 & 0 \\
\hline Birth trauma & 1 & 0 \\
\hline Long-bone fracture & 0 & 2 \\
\hline Other bone fracture & 1 & 0 \\
\hline Facial-nerve injury at $72 \mathrm{~h}$ of age or at discharge & 0 & 1 \\
\hline Intracerebral hemorrhage & 1 & 1 \\
\hline Apgar score $<4$ at $5 \mathrm{~min}$ & 1 & 4 \\
\hline \multicolumn{3}{|l|}{ Abnormal level of consciousness } \\
\hline Stupor or decreased response to pain & 4 & 2 \\
\hline Hyperalert, drowsy, or lethargic & 0 & 1 \\
\hline $\begin{array}{l}\text { Assisted ventilation for } \geq 24 \mathrm{~h} \text { by means of endotracheal tube, } \\
\text { inserted within } 72 \mathrm{~h} \text { after birth }\end{array}$ & 0 & 2 \\
\hline Cystic periventricular leukomalacia & 1 & 0 \\
\hline
\end{tabular}

comparison. $\mathrm{P}<0.05$ was considered to indicate a statistically significant difference.

\section{RESULTS}

\section{Characteristics of pregnant woman at baseline}

There were 343 pregnant women who were randomly divided into PCD and PVD groups (208 vs 135) between October 2013 and March 2015. Table 1 showed that baseline characteristics of the two study groups were similar. The PCD group [162/208 (77.88\%)] and the PVD group [108/135 (80.00\%)] underwent randomization between 224 days and 258 days of gestation, respectively.

\section{Characteristics of labor and delivery for pregnant woman}

As shown in Table 2, the labor and delivery outcomes for all women were as follows: the planned-cesarean-delivery group, 187 (89.90\%) pregnant women, 2 (0.96\%) pregnant women and 19 (9.13\%) pregnant women appeared cesarean for both infant, Vaginal and cesarean, and Vaginal for both, respectively; in the planned-vaginal delivery group, 51 (37.77\%) pregnant women, 7 (5.19\%) pregnant women and 77 (57.04\%) pregnant women appeared cesarean for both infant, Vaginal and cesarean, and Vaginal for both, respectively. Timing of cesarean sections were higher in the planned-cesarean-delivery group than those in the planned-vaginal delivery group. There were no significant differences in other factors between the planned-vaginal delivery group and planned-vaginal delivery group.

\section{Pregnancies outcomes}

As shown in Table 3, the primary outcome was notably associated with gestational age at randomization. However, other factors between the PVD group and the PCD group were not related with primary outcome.

\section{Pregnant outcomes}

There was no significant difference in the frequency of the maternal composite outcome between the planned-cesarean-delivery and planned-delivery groups (Tab. 4). During the trial, all adverse events documented were measured composing the morbidity component of the primary outcome. However, there was no other adverse outcome reported to the data and safety monitoring board.

\section{DISCUSSION}

With the development of assisted reproductive technology, ratio of gemellary pregnancy worldwide is significantly increasing and distocia is more challenging to modern Obstetrics and Gynaecology [18]. In recent years, vaginal delivery rates of twins were decreasing while cesarean section rates were increasing year by year [19]. It was reported that in China, vaginal delivery rates of twins in 2010 were $78.45 \%$ [10]. As a result, how to select a suitable delivery method and reduce cesarean section rates is an issue that needs to be 


\begin{tabular}{|l|l|l|}
\hline Table 4. Pregnant outcomes & \multicolumn{2}{l|}{ Vaginal delivery (n= 135) } \\
\hline Characteristic & Cesarean deliver $\mathbf{( n = 2 0 8 )}$ & $8(5.93 \%)$ \\
\hline Death or serious maternal morbidity & $14(6.7 \%)$ & $8(5.93 \%)$ \\
\hline Hemorrhage & $14(6.73 \%)$ & $4(2.96 \%)$ \\
\hline Blood loss $\geq 1500 \mathrm{~mL}$ & $5(2.04 \%)$ & $8(5.93 \%)$ \\
\hline Blood transfusion & $12(5.77 \%)$ & $3(2.22 \%)$ \\
\hline Dilation and curettage of uterus after delivery & $3(1.44 \%)$ & $1(0.74 \%)$ \\
\hline Laparotomy & $2(0.96 \%)$ & $1(0.74 \%)$ \\
\hline Genital tract injury & $1(0.48 \%)$ & $1(0.74 \%)$ \\
\hline Perineal third- or fourth-degree tear involving anal sphincter & 0 & $2(1.48 \%)$ \\
\hline Thromboembolism requiring anticoagulant therapy & 0 & $1(0.74 \%)$ \\
\hline Infection, excluding wound infection & $2(0.96 \%)$ & $2(1.48 \%)$ \\
\hline Wound infection & $7(3.37 \%)$ & $2(1.48 \%)$ \\
\hline Infection requiring prolongation of hospital stay & $5(2.04 \%)$ & $1(0.74 \%)$ \\
\hline Infection requiring readmission to hospital & $2(0.96 \%)$ & $1(0.74 \%)$ \\
\hline Infection requiring repeated treatment as an outpatient & $5(2.04 \%)$ & $8(5.93 \%)$ \\
\hline Wound dehiscence or breakdown & $14(6.73 \%)$ & 0 \\
\hline Major serious or life-threatening medical illness & $3(1.44 \%)$ & \\
\hline
\end{tabular}

solved urgently. In the present study, the results verified $162 / 208$ (77.88\%) pregnant women in the PCD group and $108 / 135$ (80.00\%) pregnant women in the PVD group underwent randomization between 224 days and 258 days of gestation.

When pregnant women feel hyperinflation in abdomen, expiatory dyspnea or serious illness, pregnancy should be terminated [20]. Furthermore, when women have premature rupture of fetal membranes or about to give birth during $28^{\text {th }}-34^{\text {th }}$ week, pregnancy should be terminated after fetal lung maturating [10]. Finally, pregnancy termination should be considered when complications occur, and pregnancy cannot be continued [13]. When the expected date of confinement reaches but delivery does not occur, women should be admitted to hospital and termination of the pregnancy should be considered [7]. Like a singleton pregnancy, delivery time of a gemellary pregnancy should comprehensively consider maternal complications and fetal situations in the uterus [21]. When the intrauterine environment is obviously not suitable to fetus growth and this condition cannot be improved by intrauterine therapy, it is the appropriate time to terminate the pregnancy [22]. Therefore, delivery time is dependent on specific conditions of pregnant women. Physician should communicate with women and their families as well as confirm gestational weeks. The present study showed that 87 (89.90\%) pregnant women of the planned-cesarean-delivery group appeared cesar- ean for both infant and 77 (57.04\%) pregnant women of the planned-vaginal delivery group appeared vaginal for both infants. The timing of cesarean sections were higher in the PCD group than those of the PVD group.

In recent years, with rapid advances of medical technology, cesarean techniques are significantly improving and rates of cesareans in China are continuous increasing [10]. However, cesareans may cause changes of uterus position or anteversion of uterus. As uterine contraction at uterine incision is weak, cesareans would seriously affect subsequent delivery [23]. Compared with normal labor, cesareans produce more bleeding and involution of uterus is slower [24]. Meanwhile, lactation and discharge of meconium for newborns delay while peak time of jaundice are later and more serious. Moreover, it would increase the possibilities of maternal and neonatal complications [25]. Consequently, the medical field is still confronted with the issue of how to select subsequent deliveries after a cesarean section. In the present study, significantly related to the primary outcome was gestational age at randomization in two groups.

In conclusion, these data indicate that there were no benefits of planned cesarean section with the delivery of twins between 32 and 38 weeks of gestation in comparison to planned vaginal delivery, if the first twin was in the cephalic presentation. The risk of fetal or neonatal death or serious neonatal morbidity of planned-vaginal-delivery was like those of planned-vaginal-delivery in pregnant woman with twin pregnancy. 


\section{REFERENCES:}

1. Martin JA, Hamilton BE, Osterman MJK, et al. Births: final data for 2016. Natl Vital Stat Rep. 2018; 67: 1-52.

2. Aviram A, Lipworth $\mathrm{H}$, Asztalos EV, et al. The worst of both worlds-combined deliveries in twin gestations: a subanalysis of the Twin Birth Study, a randomized, controlled, prospective study. Am J Obstet Gynecol. 2019; 221(4): 353.e1-353.e7, doi: 10.1016/j.ajog.2019.06.047, indexed in Pubmed: 31254526.

3. Hehir MP, Ananth CV, Siddiq Z, et al. Cesarean delivery in the United States 2005e2014: a populationbased analysis using the Robson Ten-Group Classification System. Am J Obstet Gynecol . 2018; 219: 105. e1-111.e1.

4. Robson SJ, de Costa C, Woods C, et al. Maternal-choice caesarean section versus planned vaginal birth in low-risk primigravid women. Aust N Z J Obstet Gynaecol. 2018; 58(4): 469-473, doi: 10.1111/ajo.12766, indexed in Pubmed: 29359505.

5. Loscul C, Schmitz T, Blanc-Petitjean P, et al. JUMODA and MEDIP study groups. Risk of cesarean after induction of labor in twin compared to singleton pregnancies. Eur J Obstet Gynecol Reprod Biol. 2019; 237: 68-73, doi: 10.1016/j.ejogrb.2019.04.005, indexed in Pubmed: 31022655.

6. Khalil A, Giallongo E, Bhide A, et al. Reduction in twin stillbirth following implementation of NICE guidance. Ultrasound Obstet Gynecol. 2020 [Epub ahead of print], doi: 10.1002/uog.22051, indexed in Pubmed: 32304623.

7. Sundram V, Chauhan SC, Ebeling M, et al. Curcumin attenuates $\beta$-catenin signaling in prostate cancer cells through activation of protein kinase D1. PLoS One. 2012; 7(4): e35368, doi: 10.1371/journal.pone.0035368, indexed in Pubmed: 22523587.

8. Yun SM, Jung JiH, Jeong SJ, et al. Tanshinone IIA induces autophagic cell death via activation of AMPK and ERK and inhibition of mTOR and p70 S6K in KBM-5 leukemia cells. Phytother Res. 2014; 28(3): 458-464, doi: 10.1002/ptr.5015, indexed in Pubmed: 23813779.

9. Shan $X L$, Zhou XY, Yang J, et al. [Inhibitory effect of cucurbitacin $E$ on the proliferation of ovarian cancer cells and its mechanism]. Chin J Cancer. 2010; 29(1): 20-24, doi: 10.5732/cjc.009.10223, indexed in Pubmed: 20038305.

10. Wang Z, LiY, Banerjee S, et al. Down-regulation of Notch-1 and Jagged-1 inhibits prostate cancer cell growth, migration and invasion, and induces apoptosis via inactivation of Akt, mTOR, and NF-kappaB signaling pathways. J Cell Biochem. 2010; 109(4): 726-736, doi: 10.1002/jcb.22451, indexed in Pubmed: 20052673.

11. Lan $T$, Wang $L, X u Q$, et al. Growth inhibitory effect of Cucurbitacin $E$ on breast cancer cells. Int J Clin Exp Pathol. 2013; 6(9): 1799-1805, indexed in Pubmed: 24040444.

12. Li CM, Narayanan R, Lu Y, et al. 2-Arylthiazolidine-4-carboxylic acid amides (ATCAA) target dual pathways in cancer cells: $5^{\prime}$-AMP-activated protein kinase (AMPK)/mTOR and PI3K/Akt/mTOR pathways. Int J Oncol. 2010; 37(4): 1023-1030, indexed in Pubmed: 20811725.

13. Zha $Q B$, Zhang $X Y$, Lin $Q R$, et al. Cucurbitacin $E$ Induces Autophagy via Downregulating mTORC1 Signaling and Upregulating AMPK Activity.
PLoS One. 2015; 10(5): e0124355, doi: 10.1371/journal.pone.0124355, indexed in Pubmed: 25970614.

14. Duncan KL, Duncan MD, Alley MC, et al. Cucurbitacin E-induced disruption of the actin and vimentin cytoskeleton in prostate carcinoma cells. Biochem Pharmacol. 1996; 52(10): 1553-1560, doi: 10.1016/s00062952(96)00557-6, indexed in Pubmed: 8937470.

15. Asztalos EV, Hannah ME, Hutton EK, et al. Twin Birth Study Collaborative Group, Twin Birth Study Collaborative Group. A randomized trial of planned cesarean or vaginal delivery for twin pregnancy. N Engl J Med. 2013; 369(14): 1295-1305, doi: 10.1056/NEJMoa1214939, indexed in Pubmed: 24088091

16. Keane M, Smith GCS, White IR, et al. Planned cesarean or vaginal delivery for twin pregnancy. N Engl J Med. 2014; 370(3): 280-280, doi: 10.1056/NEJMc1314560, indexed in Pubmed: 24428474.

17. Goossens SM, Mol BWJ, Nijhuis JG. Vaginal delivery safe for twins starting at 32 weeks? . Ned Tijdschr Geneeskd. 2014(158): A7226.

18. Sun $C$, Zhang $M$, Shan $X$, et al. Inhibitory effect of cucurbitacin $E$ on pancreatic cancer cells growth via STAT3 signaling. J Cancer Res Clin Oncol. 2010; 136(4): 603-610, doi: 10.1007/s00432-009-0698-x, indexed in Pubmed: 19816711.

19. Kawakami J, Cowan JE, Elkin EP, et al. CaPSURE Investigators. Androgen-deprivation therapy as primary treatment for localized prostate cancer: data from Cancer of the Prostate Strategic Urologic Research Endeavor (CaPSURE). Cancer. 2006; 106(8): 1708-1714, doi: 10.1002/cncr.21799, indexed in Pubmed: 16544313.

20. Zhu B, Fukada K, Zhu H, et al. Prohibitin and cofilin are intracellular effectors of transforming growth factor beta signaling in human prostate cancer cells. Cancer Res. 2006; 66(17): 8640-8647, doi: 10.1158/00085472.CAN-06-1443, indexed in Pubmed: 16951178.

21. Huang WW, Yang JS, Lin MW, et al. Cucurbitacin E Induces G(2)/M Phase Arrest through STAT3/p53/p21 Signaling and Provokes Apoptosis via Fas/CD95 and Mitochondria-Dependent Pathways in Human Bladder Cancer T24 Cells. Evid Based Complement Alternat Med. 2012; 2012: 952762, doi: 10.1155/2012/952762, indexed in Pubmed: 22272214

22. Brown RE, Zotalis $\mathrm{G}$, Zhang $\mathrm{PL}$, et al. Morphoproteomic confirmation of a constitutively activated mTOR pathway in high grade prostatic intraepithelial neoplasia and prostate cancer. Int J Clin Exp Pathol. 2008; 1(4): 333-342, indexed in Pubmed: 18787612.

23. Deeb D, Gao X, Jiang $H$, et al. CDDO-me induces apoptosis and inhibits Akt, mTOR and NF-kappaB signaling proteins in prostate cancer cells. Anticancer Res. 2007; 27(5A): 3035-3044, indexed in Pubmed: 17970042.

24. Nakashima S, Matsuda $\mathrm{H}$, Kurume Ai, et al. Cucurbitacin $\mathrm{E}$ as a new inhibitor of cofilin phosphorylation in human leukemia U937 cells. Bioorg Med Chem Lett. 2010; 20(9): 2994-2997, doi: 10.1016/j.bmcl.2010.02.062, indexed in Pubmed: 20347305.

25. Kong $Y$, Chen J, Zhou Z, et al. Cucurbitacin E induces cell cycle G2/M phase arrest and apoptosis in triple negative breast cancer. PLoS One. 2014; 9(7): e103760, doi: 10.1371/journal.pone.0103760, indexed in Pubmed: 25072848 . 